\title{
Distal biliary stricture as a complication of sclerosant injection for bleeding duodenal ulcer
}

\author{
W Luman, N Hudson, C P Choudari, M A Eastwood, K R Palmer
}

\begin{abstract}
A patient undergoing repeated endoscopic injection therapy for important bleeding from a duodenal ulcer developed intestinal perforation followed by extrahepatic obstructive jaundice resulting from benign biliary stricture. It is proposed that these complications were a consequence of the use of ethanolamine oleate as part of the injection regimen and caution against the use of this material is needed, particularly as current clinical trials suggest that sclerosants offer no advantage over injection therapy with dilute adrenaline alone.

(Gut 1994; 35: 1665-1667)
\end{abstract}

Endoscopic injection therapy improves the prognosis of patients presenting with peptic ulcer haemorrhage. ${ }^{1-6}$ Published studies have used a variety of injection agents including dilute adrenaline, polidocanol, absolute alcohol, and ethanolamine oleate in a variety of combinations and concentrations, but the safest and most effective regimen is unclear. Sclerosants are potentially dangerous ${ }^{7-12}$ and studies are conflicting as to whether they are a necessary adjunct to adrenaline; for example Lin et al reported that a combination of 1:10000 adrenaline and absolute alcohol was a more effective treatment than dilute adrenaline, ${ }^{13}$ while others have not found this. ${ }^{14} 15$

Endoscopic injection therapy seems remarkably safe but we report a hitherto unrecognised complication of sclerosant injection for bleeding duodenal ulcer.

Gastroenterology Unit, Western General Hospital, Edinburgh W Luman N Hudson

C P Choudari

M A Eastwood

K R Palmer

Correspondence to: Dr W Luman,

Gastroenterology Unit,

Western General Hospital,

Crewe Road, Edinburgh EH4 2XU.

Accepted for publication 17 February 1994 lar failure. In addition she had a previous history of chronic obstructive airways disease and idiopathic thrombocytopenic purpura. On admission the pulse rate was 120 beats per minute, the systolic blood pressure was $80 \mathrm{~mm} \mathrm{Hg}$, and she displayed epigastric tenderness. The haemoglobin concentration was $76 \mathrm{~g} / \mathrm{l}$, platelets $205 \times 10^{9} / 1$, prothrombin time $1 \cdot 0$, urea $8.7 \mathrm{mmol} / 1$, liver function tests were normal. After resuscitation with intravenous colloid and blood, she had an endoscopy, which showed a $15 \mathrm{~mm}$ anterior duodenal ulcer with a visible spurting vessel in its base. The ulcer was injected with $3 \mathrm{ml}$ of 1:100 000 adrenaline and the vessel stopped bleeding. She received four units of blood and was discharged on the fifth day while taking omeprazole $40 \mathrm{mg}$ every day. The following day she was readmitted with further haematemesis. On this occasion she was haemodynamically stable and her haemoglobin concentration was $96 \mathrm{~g} / \mathrm{l}$. She had a further endoscopy at which the bleeding duodenal ulcer was again seen. The vessel was reinjected with $8 \mathrm{ml}$ of adrenaline 1:100 000. After consultation with our surgical colleagues it was decided to treat her conservatively and endoscopy was repeated 48 hours later. The vessel in the ulcer base remained protuberant and was again injected with $3 \mathrm{ml}$ adrenaline 1:100 000 and on this occasion, an additional injection of $0.5 \mathrm{ml}$ of $5 \%$ ethanolamine was placed directly into the vessel. She remained haemodynamically stable after this third therapeutic endoscopy. Five days later, however,

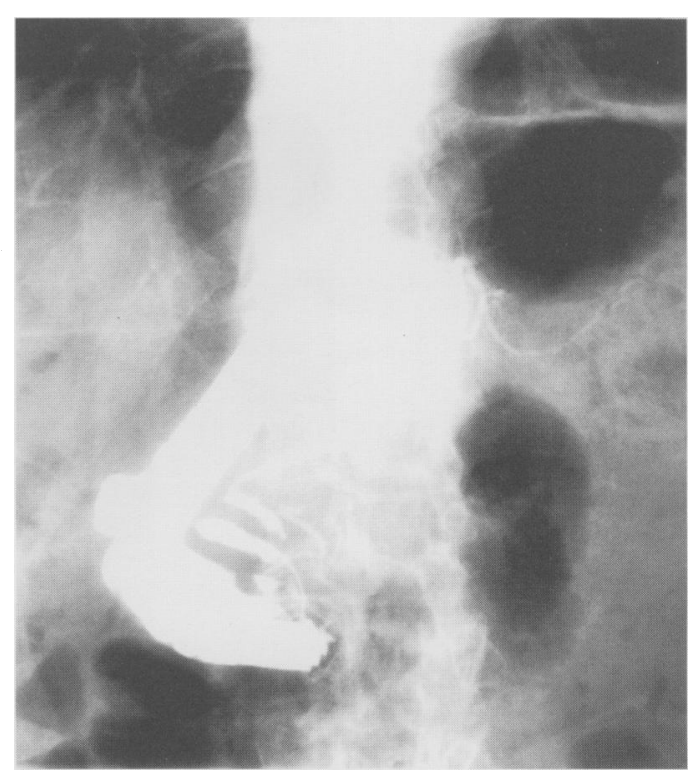

Figure 1: Endoscopic retrograde cholangiography showing complete obstruction in the lower common bile duct compounding to displacement of the main pancreatic duct. 


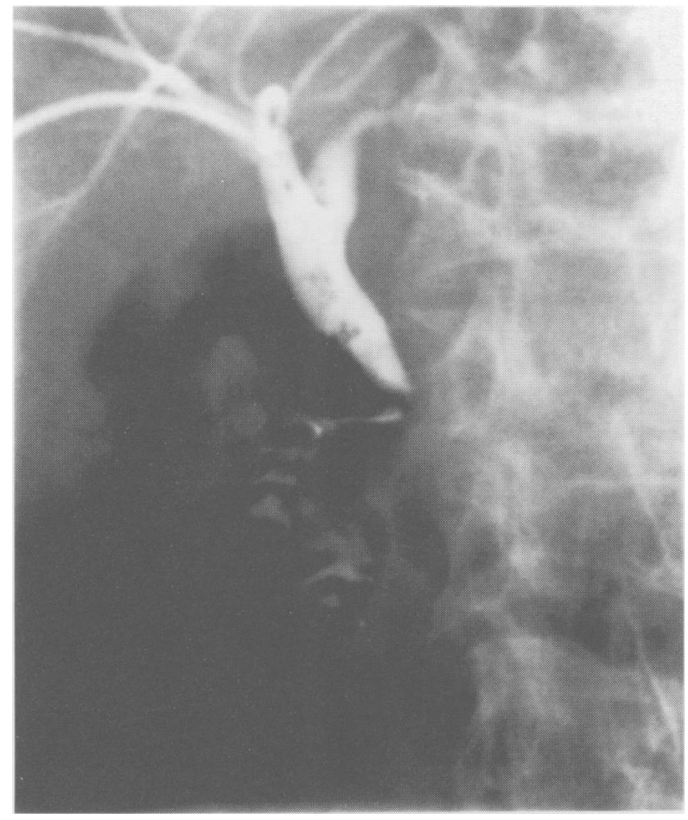

Figure 2: Percutaneous cholangiography confirming the distal biliary stricture and also showing a fistula to the first part of the duodenum.

she developed fever, confusion, abdominal tenderness and guarding. A chest radiograph showed free subdiaphragmatic air. The presumed ulcer perforation was treated conservatively with intravenous fluids, nasogastric suction, and antibiotics and she was discharged on the 15th day.

On review in outpatients eight weeks later the patient complained of tiredness and general malaise but denied abdominal pain or vomiting. On examination she was mildly icteric. Serum liver function tests showed: alkaline phosphatase concentration of $1100 \mathrm{U} / 1$, bilirubin 40 $\mathrm{mmol} / \mathrm{l}$, alanine transaminase $579 \mathrm{U} / 1$. An upper abdominal ultrasound scan showed normal liver texture but the common bile duct was dilated to $16 \mathrm{~mm}$ in diameter. Endoscopic retrograde cholangiopancreatography showed a tight smooth stricture in the distal common bile duct and the distal pancreatic duct was

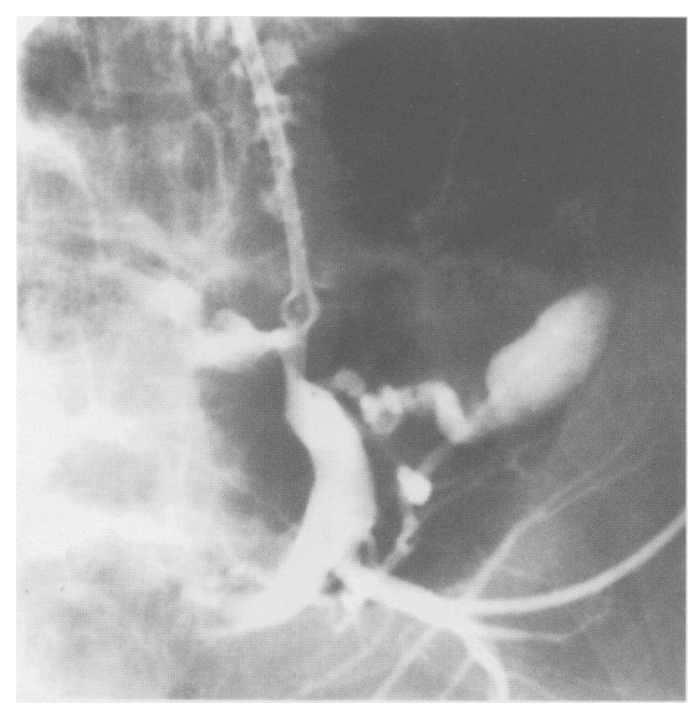

Figure 3: Percutaneous cholangiography showing the $12 \mathrm{~F}$ double mushroom stent in situ. displaced towards the common bile duct (Fig 1). After endoscopic retrograde cholangiopancreatography there was spontaneous improvement in her liver function tests; alkaline phosphatase $618 \mathrm{U} / \mathrm{h}$, bilirubin $12 \mu \mathrm{mol} / \mathrm{l}$, alanine transaminase $107 \mathrm{U} /$. At percutaneous transhepatic cholangiography the biliary stricture was again noted but a fistulous tract had formed between the common bile duct proximal to the stricture and the first part of the duodenum (Fig 2). The stricture was dilated with a balloon and a $12 \mathrm{~F}$ double mushroom biliary stent was inserted percutaneously (Fig 3). Subsequently the liver function tests normalised and the stent was removed six weeks later.

\section{Discussion}

Endoscopic injection therapy is now commonly used to treat bleeding peptic ulcer. ${ }^{1}$ The most effective and safest injection regimen is not yet established and different groups have reported comparable results using dilute adrenaline alone, ${ }^{2}$ sclerosants alone, ${ }^{4}$ and combination treatment. ${ }^{56}$ Injection therapy is generally regarded as safe but isolated reports of complications have appeared and these have usually occurred after the use of sclerosants. ${ }^{712}$ Furthermore, studies from our own group and from Hong Kong have suggested that the addition of sclerosants to dilute adrenaline confers no benefit in terms of stopping bleeding or preventing rebleeding. 1415

This case report adds to the increasing number of complications associated with sclerosant injection. We suggest that both the intestinal perforation and the biliary stricture were a complication of ethalonamine oleate therapy. Clearly we cannot exclude a spontaneous ulcer perforation and subsequent inflammatory reaction leading to the biliary problem but this seems unlikely. The patient's treatment was consistently conservative, principally because her poor general condition precluded surgical intervention. We would argue that her initial presentation at a great age with important bleeding from a giant duodenal ulcer with a background of chronic obstructive airways disease and ischaemic heart disease put her at a very high risk of postoperative death should surgical intervention have been undertaken. Avoidance of surgery by endoscopic injection almost certainly prevented death, but it might be argued that a surgical operation after haemostasis and resuscitation would have avoided the series of complications described in this report. The timing of surgery is clearly diffcult and we do not yet have sufficient information to make reasoned decisions in such cases.

$1 \mathrm{NIH}$ consensus conference on therapeutic endoscopy and bleeding. FAMA 1989; 262: 1369-72.

2 Chung SCS, Leung JWC, Steele RJC, Crofts TJ, Li AKC. Endoscopic injection of adrenaline for actively bleeding ulcers: a randomised trial. $B M \mathcal{F}$ 1988; 296: 1631-3.

3 Oxner RBG, Simmonds NJ, Gertner DJ, Nightingale JND, Burnham WR. Controlled trial of endoscopic injection treatment for bleeding from peptic ulcer with visible vessels. Lancet 1992; 339: 966-8.

4 Sugawa C, Fugita Y, Ikeda T, Walt AJ. Endoscopic haemostasis of bleeding of the upper gastrointestinal tract by local injection of ninety eight percent dehydrated ethanol. Surg Gynecal Obstet 1986; 162: 159-63. 
5 Panes J, Viver J, Forne M, Garcia-Olivares E, Marco C, Garau J. Controlled trial of endoscopic sclerosis in bleeding peptic ulcers. Lancet 1987; ii: 1292-4.

6 Raigopal C, Palmer KR. Endoscopic injection sclerosis: effective treatment for bleeding peptic ulcer. Gut 1991; 32: 727-9.

7 Chester JF, Hurley PR. Gastric necrosis: a complication of endoscopic sclerosis for bleeding peptic ulcer. Endoscopy 1990; 22: 287.

8 Loperfido S, La Torre L. Extensive necrosis of gastric mucosa following injection therapy of bleeding peptic ulcer. Endoscopy 1990; 22: 285-6.

9 Dell'Abate P, Spaggiari L, Carboynani P. An unusual complication of sclerotherapy. Endoscopy 1991; 23: 352-3.

10 Cappeli J, Dryjski J, Rahier I, Ramdani B, Lamy V, Moisse R. Another severe complication of sclerotherapy for bleeding peptic ulcer. Endoscopy 1993; 25: 431-2.
11 Levy J, Khakoo S, Barton R, et al. Fatal injection sclerotherapy of a bleeding peptic ulcer. Lancet 1991; 337: 504.

12 Meissner K, Jirikowski B. Stomach wall slough and ulcer perforation following endoscopic injection haemostasis with polidocanol. Endoscopy 1993; 25: 185-7.

13 Lin HJ, Perng CL, Lee SD. Is sclerosant injection mandatory after an epinephrine injection for arrest of peptic ulcer haemorrhage? A prospective, randomised, comparative study. Gut 1993; 34: 1182-5.

14 Choudari CP, Palmer KR. Endoscopic injection therapy for bleeding peptic ulcer; a comparison of adrenaline alone with adrenaline plus ethanolamine oleate. Gut 1994; 35: 608-10.

15 Chung SCS, Lueng JWC, Leong HT, Lo KK, Li AKC. Adding a sclerosant to endoscopic epinephrine injection in actively bleeding ulcers: a randomized trial. Gastrointest Endosc 1993; 39: 611-5. 